\title{
Sedentarismo, nós e o mundo (im)possível no contexto da ciência
}

\section{Sedentarism, we and the (im)possible world on the context of science}

Ilhéus, 6 de maio de 2007.

Prezados Editores,

A perspectiva de análise densa e original do artigo de Castiel \& Álvarez-Dardet, ${ }^{3}$ publicado no número 41(3) da Revista de Saúde Pública, oferece valiosa oportunidade para comentarmos sobre a temática do sedentarismo presente em produções científicas dos últimos anos, que vem se difundindo no campo sanitário. Associado ao estilo de vida, como enfoque de excessiva responsabilização individual nos problemas da saúde populacional, tornou-se uma espécie de símbolo emblemático da era persecutória em que vivemos.

Nos interessa aqui ampliar o diálogo com os autores acerca de dimensões moralizantes da culpabilização preventiva de comportamentos cotidianos, tidos como insalubres ou "de risco", a partir de interpretações epidemiológicas colocadas em circulação pelos meios de comunicação de massa. ${ }^{5}$ Mas, sobretudo, é imperativo registrar que essas concepções preocupantes, signatárias de persuasivos discursos hibridizados entre ciência e mídia, têm orientado hegemonicamente formas de pensar e intervir sobre o processo saúde/doença/cuidado.

Supondo que o combate ao sedentarismo seja realmente um objetivo plausível para as preocupações em saúde pública, como fazê-lo sem estigmatizar os sujeitos classificados como sedentários?

A demonização do sedentarismo e, por conseguinte do sedentário, tem figurado em certas perspectivas retóricas (associando-o a doenças crônico-degenerativas) escudada na contabilização probabilística (futura) de gastos inaceitáveis para os cofres públicos, possíveis de se evitar - segunda essa ótica - caso determinados comportamentos sejam adotados ou modificados. ${ }^{4}$ Há uma clara tentativa de estabelecer convencimento argumentativo por meio de inferências causais estatísticas, ancorado em uma lógica econômica que, curiosamente, sobrepõe e antecede as próprias preocupações sanitárias.
Outro efeito adverso daí decorrente é o deslocamento dos valores e significados das práticas contemporâneas de cuidado com o corpo e a saúde, que vêm habitando o imaginário social de nossas coletividades, impregnados por uma perspectiva impositiva, medicalizada, culpabilizante, agenciadora a priori do contingente de gastos calóricos para evitação de riscos e agravos.

Ademais, cabe indagar se a categoria "sedentário" se aplicaria, por exemplo: aos operários da construção civil cujas jornadas diárias são longas e árduas e, freqüentemente desprovidas de horas de lazer (por falta de condições financeiras e/ou pelo cansaço físico proveniente do trabalho); ou aos "bóias frias" das colheitas de canaviais brasileiros, que têm morrido por excesso de atividade física laboral em troca de remunerações irrisórias (e dos quais pouco se vê noticiado na mídia). Sob esse enfoque socioeconômico, a classificação torna-se despropositada, bem como a preconização das mudanças de comportamento (estilo de vida) inferida a partir de investigações epidemiológicas que advogam a relevância do suposto problema.

Como ressalta Castiel, ${ }^{2}$ "uma crítica comum ao conceito 'estilo de vida' está referido ao seu emprego em contextos de miséria e aplicado a grupos sociais onde as margens de eleição praticamente inexistem. Muitas pessoas não elegem 'estilos' para levar suas vidas. Não há opções disponíveis. Na verdade, nestas circunstâncias, o que há são estratégias de sobrevivência". [grifo do autor] (p. 93)

Os argumentos arrolados em pesquisas sobre o sedentarismo colocam em relevo um certo estilo de pensamento ${ }^{4}$ e uma escolha ética da verdade 5 que implica de forma axiomática, aceitar ou não a pertinência desse tipo de categorização. Quando incorporada em investigações sobre mapeamento de riscos à saúde, fica subsumida a elevação de seu grau de importância em detrimento de outras questões a serem consideradas. Conforme enunciam Castiel \& Álvarez-Dardet ${ }^{3}$ é 
certo que a orientação conceitual de qualquer estudo científico perfila uma determinada concepção de ser humano, de sociedade que se deseja e os modos de alcançá-la.

Esse empobrecimento epistemológico e ontológico, de certo modo, já vem sendo criticado por analistas do campo quanto à epidemiologia moderna estar se distanciando progressivamente das preocupações coletivas de sua origem histórica, em detrimento da opção por outros objetos investigativos. ${ }^{1}$

\section{REFERÊNCIAS}

1. Barata RB. Epidemiologia no século XXI: perspectivas para o Brasil. Rev Bras Epidemiol.1999;2(1/2):6-18.

2. Castiel LD. Quem vive mais, morre menos? Estilos de risco e promoção de saúde. In: Bagrichevsky M, Palma A, Estevão A, organizadores. A saúde em debate na educação física. Blumenau: Edibes; 2003. p. 79-97.
Marcos Bagrichevsky

Adriana Estevão

Departamento de Ciências da Saúde Universidade Estadual de Santa Cruz, Ilhéus, BA

Paulo Roberto Vasconcellos-Silva

Faculdade de Medicina

Universidade Federal do Estado do Rio de Janeiro, Rio de Janeiro, RJ
3. Castiel LD, Álvarez-Dardet C. La salud persecutoria. Rev Saude Publica. 2007;41(3):461-6.

4. Lupton D. Risk. London: Sage; 1995.

5. Vaz P, Pombo M, Fantinato M, Pecly G. O fator de risco na mídia. Interface. 2007;11(21):145-53.

\section{Resposta do autor}

Rio de Janeiro, 21 de junho de 2007.

Prezados Editores,

A carta de Bagrichevsky e co-autores é bastante feliz e oportuna para estimular o debate propiciado pela Revista de Saúde Pública. A reflexão acerca do sedentarismo ilustra com propriedade o tema abordado no artigo "La salud persecutoria".

Seguindo neste caminho, Edwards ${ }^{1}$ apresenta ironicamente os extremos das propostas de promoção de estilos de vida saudável em relação ao contexto dos países economicamente avançados. Consistem em tópicos comparativos para a boa saúde - a partir da perspectiva de estilo de vida e do ponto de vista dos determinantes sociais da saúde. Eis algumas:

Estilo de vida:

- Não fume. Se puder, pare. Se não puder, reduza.

- Siga uma dieta equilibrada e suficiente em frutas e vegetais.

- Mantenha-se fisicamente ativo.

- Administre o estresse, por exemplo, conversando sobre o que lhe aflige e buscando tempo para relaxar.

- Se ingerir álcool, faça-o com moderação.

- Proteja-se e às crianças das queimaduras do sol.

- $\quad$ Pratique sexo seguro.

Determinantes sociais de saúde:

- Não seja pobre. Se puder, pare. Se não puder, tente não ficar pobre por muito tempo.

- Não tenha pais pobres.

- Seja proprietário de veículo.

- Não trabalhe em atividades estressantes e mal pagas.

- Não resida em moradias úmidas, de baixa qualidade.

- Tenha condições econômicas para sair de férias e tomar banhos de sol.

- Pratique não perder seu emprego e ficar desempregado.

Além disso, cabe lembrar que, em algumas práticas outdoors de exercício físico é preciso estar em um estado de alerta constante de forma a prestar alguma atenção para aqueles "intrusos" de distinto estilo de vida capazes de espreitar com olhos ameaçadores àqueles que se dedicam ao estilo de vida anti-sedentarismo. 
Para aqueles com acesso às benesses tecnológicas, ainda é preciso considerar que quando a política se torna biopolítica e toma a saúde e, por extensão, a vida como objeto de intervenção preventiva total, priva-a de sua dimensão de abertura, restringindo-a aos ditames relativos ao privilégio à longevidade biológica.

Os mecanismos de proteção e preservação da saúde passam consistir na negação da vida e na sustentação da sobrevida. Trazendo o filósofo político italiano Roberto Esposito ${ }^{2}$ para o contexto da saúde, preservar a vida significa transitar pela lógica imunitária - a busca compulsiva de imunidade de modo a afastar os riscos à saúde que supostamente poderiam nos afetar e nos vitimar. Para se viver muito tempo é imprescindível à vigilância extensiva e normalizadora que pode acabar impedindo a possibilidade de abertura e estimulando o conformismo.

Viver sob a égide biopolítica é perpetuar a vida por meio do sacrifício existencial do ser vivente, reduzindo-o ao âmbito biológico. Na saúde persecutória, vive-se sob o primado paradoxal da sentença e da condenação culposa sem delito como estratégia de afastamento dos riscos à sobrevida, que, para ser mantida sob esta forma, passa a ser achatada aos limites somáticos ao preço da negação do mais humano que há na vida. Nessa dimensão, descarta-se a valorização ética das experiências corporais "livres" dos sujeitos, como possibilidades de realização singular, como formas mais humanas de ser e sentir-se saudável (ou não). Cada vez mais importa discutirmos não apenas qualidade de vida, mas também essa quantificação da vida, analisando criticamente custos e benefícios das propostas de longevidade a qualquer preço.

\section{REFERÊNCIAS}

1. Edwards P. Rethinking Lifestyle... From a social determinants of health perspective. Ottawa; [s.d.] [Acesso em: 28/5/2007]. Disponível em: http://www. aldergroup.com/pdf/rethinking_lifestyle.pdf

2. Esposito R. Immunitas. Protección y negación de la vida. Buenos Aires: Amorrortu; 2005.
No caso das estratégias da gestão de riscos em saúde, pela via do estilo de vida (ou mesmo da genômica), as buscas de solução que clamam por melhores análises técnico-científicas estritas não parecem dar(-se) conta das muitas dimensões possíveis para pensarmos o que seja a condição humana e as concepções do que é apropriado ou não, "bom" ou "mau", mais ou menos arriscado para cada sociedade. Todos estes "elementos" são constantemente redefinidos e negociados, nem sempre da melhor maneira, já que a própria ciência não traz respostas satisfatórias para estas questões e, por mais que tente, não resolve a contento as situações de descontrole, incerteza e complexidade que proliferam, como a que rodeia, por exemplo, a discussão acerca dos alimentos geneticamente modificados. ${ }^{3}$

Os autores da carta são bem-vindos ao se juntar a nós na tarefa de chamar, sempre que possível, a atenção quanto à insuficiência de discursos e ações de promoção de saúde baseadas no ambíguo conceito estilo de vida (em termos individuais). Por várias razões, mas basta aqui enunciar apenas uma: a perspectiva ideológica potencialmente ampliadora da distância entre pobres e ricos. Tal ponto de vista tende assim a justificar conceitualmente a exclusão de cerca de três quartos da população planetária dos benefícios provenientes da aplicação dos conhecimentos e da tecnologia em saúde.

Luis David Castiel

Escola Nacional de Saúde Pública. Fundação Oswaldo Cruz, Rio de Janeiro, RJ

3. Finucane ML, Holup JL. Psychosocial and cultural factors affecting the perceived risk of genetically modified food: an overview of the literature. Soc SCi Med. 2005;60(7):1603-1612. 